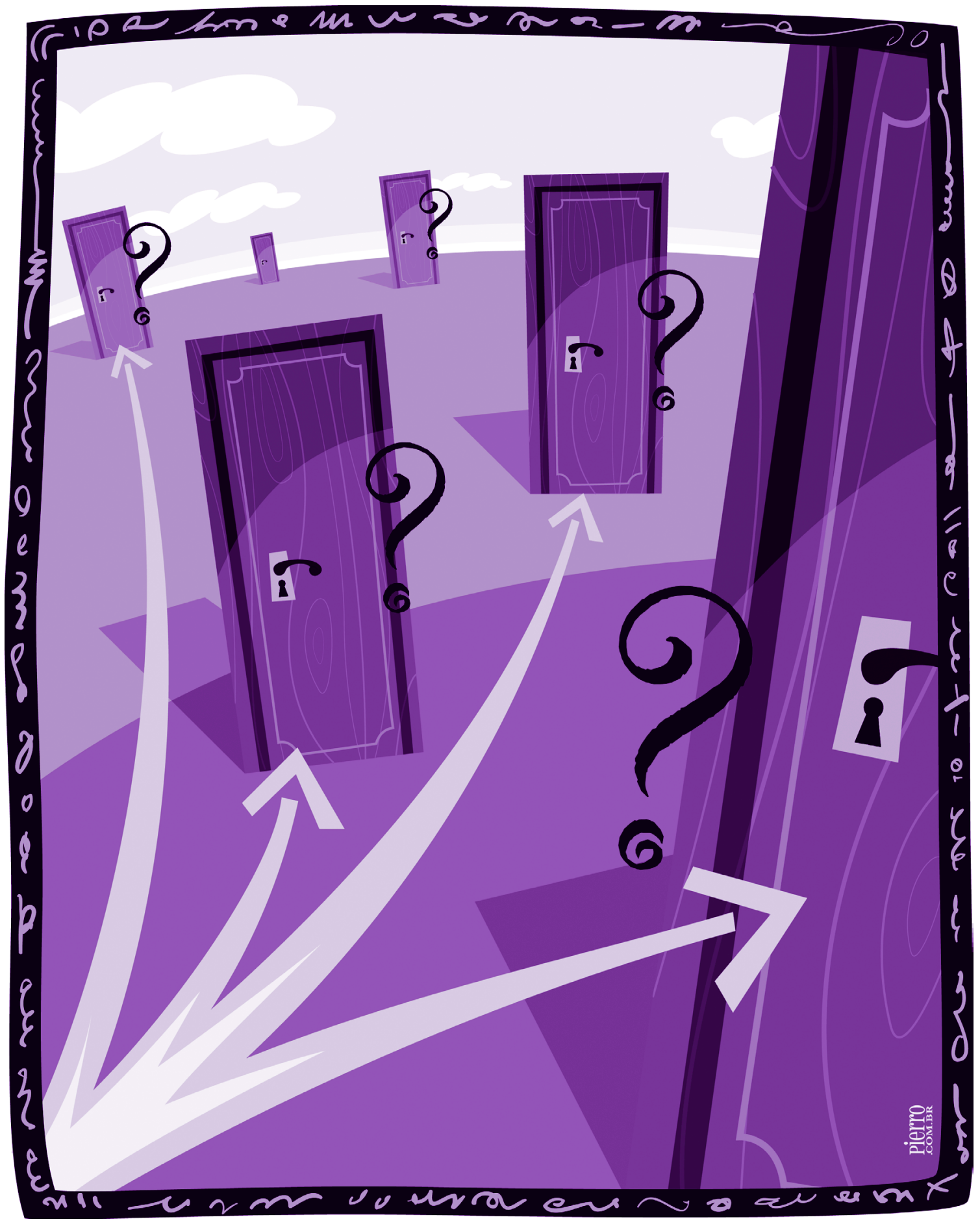




\section{A contribuição dos métodos de diagnóstico e mensuração para a Comunicação Corporativa}

Suzel Figueiredo

- Bacharel em Comunicação Social, com Habilitação em Relações Públicas, pela Fundação Armando Álvares Penteado - FAAP

- Especialista em Pesquisa de Mercado, Mídia e Opinião pela ESPM - Escola Superior de Propaganda e Marketing

- Professora de Pesquisa no curso de Relações Públicas da FAAP

- Diretora do Instituto Aberje de Pesquisa

- Diretora da SBPM - Sociedade Brasileira de Pesquisa de Mercado

- Diretora da Ideafix Estudos Institucionais

- suzel.figueiredo@ideafix.com.br 
Resumo

A pesquisa de comunicação corporativa está se estruturando no Brasil e ocupando espaço importante no planejamento e na avaliação dos programas de comunicação. Como atividade ainda incipiente, padece de critérios estabelecidos, como demonstra pesquisa realizada pelo Instituto Aberje de Pesquisa junto a empresas, assessorias de comunicação e institutos de pesquisa. A autora comenta os resultados da pesquisa aplicada à luz da teoria mais recente sobre a mensuração de resultados de relacionamentos.

PALAVRAS-CHAVE: PESQUISA - COMUNICAÇÃO CORPORATIVA - MENSURAÇÃO • AVALIAÇÃO - Planejamento

\section{Abstract}

The corporate communication research is being structured in Brazil and has been playing an important role in planning and evaluating communication programs. As it is a brand new activity, it still lacks established criteria, as shown in a research conducted by Instituto Aberje de Pesquisa with companies, communication agencies and research institutes. The author comments on the results of such research in the light of the most important theory concerning the measurement of relationship results.

KEY WORDS: RESEARCH - CORPORATE COMMUNICATION • MEASUREMENT - EVALUATION • PLANNING

\section{Resumen}

La investigación en comunicación corporativa se está estructurando en Brasil, ocupando un espacio importante en el planeamiento y en la evaluación de los programas de comunicación. Como actividad todavía incipiente, padece de criterios establecidos, como comprueba la investigación realizada por el Instituto Aberje de Investigación, junto con empresas, asesorías de comunicación e institutos de investigación.

La autora comenta los resultados de la investigación aplicada a la luz de la teoría más reciente sobre la medición de los resultados obtenidos.

PALABRAS CLAVES: INVESTIGACIÓN - COMUNICACIÓN CORPORATIVA - MEDICIÓN • EVALUACIÓN - PLANEAMIENTO 
$\mathrm{N}$ o livro Alice no País das Maravilhas, de Lewis Carroll, a menina Alice chega a uma encruzilhada na qual um gato risonho se materializa à sua frente. Alice pergunta ao gato: "Por favor, poderia me dizer qual dessas estradas devo tomar?” O gato responde: "Isso depende muito de onde quer chegar". "O lugar não importa”, diz Alice. "Então, não importa qual a estrada que tomará”, replica o gato.

Esta passagem, muito utilizada como referência em textos de administração, ilustra com propriedade a forma como algumas empresas têm realizado o planejamento de suas atividades de comunicação corporativa.

Dados de pesquisa permeiam o cotidiano das pessoas. Estão nas manchetes dos jornais, nos principais telejornais, na discussão dos temas políticos. Dados estatísticos atribuem confiabilidade aos fatos, dimensionam os problemas, classificam o comportamento da sociedade. A pesquisa, seja de opinião pública, de mercado ou social, é aceita por profissionais de todos os ramos de conhecimento como uma ferramenta útil de informação e gestão.

Não obstante a total familiaridade que a população tem com as pesquisas, os profissionais da comunicação corporativa - e entre eles os de Relações Públicas - a utilizam com restrições. Discutir essa questão é o propósito deste artigo, que está estruturado sobre dois pilares: um de fundamentação teórica da pesquisa de comunicação corporativa e outro de apresentação de uma pesquisa aplicada sob encomenda do Instituo Aberje de Pesquisa.

\section{0 que diz a teoria}

Em seu livro Planejamento de Relações Públicas na Comunicação Integrada, Margarida M. K. Kunsch (2003, p. 277) afirma que a pesquisa constitui um pré-requisito para o planejamento das Relações Públicas nas organizações. A realidade demonstra que, mesmo de forma ainda incipiente, a pesquisa corporativa vem ganhando espaço como meio de planejar, avaliar e acompanhar a implantação de projetos de comunicação. Se isso vem ocorrendo na prática, a definição teórica do que seja essa pesquisa ainda parece nebulosa, o que faz com que empresas, institutos de pesquisa e assessorias utilizem, às vezes, denominações diferentes para se referir ao mesmo assunto. 
Para uniformizar os conceitos, é importante verificar o que autores de referência na área de pesquisa de comunicação dizem sobre o tema. Lawrence Frey, Carl Botan e Gary Kreps (1999, p. 188), afirmam que a pesquisa em Comunicação deve estar focada nas mensagens. Os indivíduos que as recebem, os canais utilizados e o contexto em que ocorre a transmissão também são importantes, mas devem ser analisados apenas na medida em que possam influenciar as mensagens.

Os autores classificam os tipos de mensagens como intrapessoais, interpessoais, entre grupos, organizações e culturas/ sociedades. Além disso, dividem a pesquisa em: básica e aplicada. A primeira visa a aumentar o conhecimento sobre a comunicação e inclui testar, aprimorar e elaborar uma teoria, isto é, uma explicação generalizada a partir de um fenômeno, detalhando como ou porque ele ocorre. A pesquisa aplicada visa a resolver um problema de comunicação socialmente relevante do "mundo real". A pesquisa corporativa enquadra-se neste segundo caso.

Há, ainda, importantes características a serem destacadas na diferenciação entre pesquisas quantitativas e qualitativas. Embora se saiba que, na prática, muitas vezes uma determinada metodologia é utilizada em função do custo ou da abrangência do levantamento, no plano teórico analisa-se esta questão pelo objetivo que se quer atingir. Arthur Berger (2000, p. 49), em seu livro Media and Communication Research Methods: An Introduction to Qualitative and Quantitative Approaches, descreve cada uma das metodologias e suas características.

Os propósitos da pesquisa qualitativa são avaliar, usar conceitos para explicar, teorizar e interpretar. A quantitativa visa a medir, a processar os dados coletados, a descrever, a explicar, a predizer e a conduzir a hipóteses ou a uma teoria. O autor destaca que ambas podem ser criticadas. A primeira, porque abriria espaço a possíveis interpretações enviesadas pelos valores pessoais dos analistas, e a segunda porque pode basear-se apenas naquilo que se pode medir numericamente, ignorando outros aspectos do problema de comunicação.

Berger também divide a comunicação em cinco estratos: intrapessoal, interpessoal, pequenos grupos, organizacional e dos mass media. Para o autor, dependendo do tipo de cada uma e do que se quer investigar, é interessante usar a metodologia quantitativa, a qualitativa ou uma combinação das duas.

Essa abordagem mais ampla deixa de fora algumas questões específicas que nenhum dos autores menciona com clareza. Uma delas é qual o perfil dos entrevistados das pesquisas qualitativas. Este ponto é de especial interesse, pois muitas assessorias de comunicação realizam o que chamam de "auditorias de opinião" através de entrevistas em profundidade com públicos considerados importantes para a organização, tais como jornalistas, formadores de opinião, autoridades, dentre outros stakeholders. 
O problema é que nem sempre as assessorias responsáveis por esse tipo de trabalho seguem algumas normas importantes, que garantem a confiabilidade dos resultados. As sugestões de Berger nesse sentido são: garantir o anonimato dos entrevistados, gravar e depois transcrever as entrevistas, manter o foco das perguntas preparadas previamente, e não exprimir, seja de que maneira for, julgamentos a respeito da opinião dos entrevistados, para não incentivá-los ou constrangê-los. Em suma, é preciso ser bastante detalhista e utilizar procedimentos para garantir opiniões espontâneas.

Sabe-se, porém, que nem sempre na prática é assim, o que pode prejudicar a confiabilidade dos resultados das análises realizadas. No entanto, com a disseminação dos conhecimentos teóricos em pesquisa, muitos deles utilizados na prática e com sucesso por diversos institutos, a qualidade das pesquisas qualitativas em comunicação tende a melhorar.

Kunsch (2003, p. 281) cita inúmeros autores ligados à comunicação empresarial e, especificamente, às Relações Públicas. A necessidade e a importância da pesquisa é senso comum entre os teóricos, que enfatizam seu uso de forma científica. Broom e Dozier (apud Kunsch, 2003, p. 280) definem a pesquisa como a busca controlada, objetiva e sistemática de informação para os propósitos de descrição e entendimento.

Nota-se, claramente, como é vantajosa a união entre teoria e prática no cenário da pesquisa corporativa. Os trabalhos já realizados pelas empresas, internamente ou em parceria com assessorias e institutos, têm muito a contribuir para aperfeiçoar a teoria e esta, por sua vez, pode ajudar a aumentar a confiabilidade das informações das pesquisas que já são realizadas na prática.

\section{A questão da retenção}

Enquanto aqui no Brasil ainda se discute como mensurar para quantificar os resultados dos programas de comunicação, autores norte-americanos e europeus já estudam a mensuração da retenção da mensagem desde a década de 1990. Trata-se de um aprofundamento da avaliação da comunicação, cujo foco é a mensagem. Portanto, é mais importante identificar quais mensagens foram absorvidas pela audiência e não o tamanho da audiência atingida pela mensagem. Nesses termos, a quantificação é menos importante do que a retenção. Importa menos a quantificação e mais a retenção.

A comunicação empresarial profissional vive um momento de reavaliação de seus conceitos. Será verdadeiramente importante publicar uma revista corporativa dirigida a clientes, que recebem outras dezenas de publicações? Quais são as mensagens que o leitor consegue absorver? O impacto nos públicos de relacionamento foi relevante? Deslocaria esse questionamento para as considerações finais. 
Fraser Likely ${ }^{1}$, em seu artigo Communication and PR: Made to Measure menciona o conceito de impacto. Saber quantas pessoas foram impactadas por uma determinada mensagem é uma forma de mensuração, diz ele. Mas, o que o público ou a audiência extraiu do produto recebido, ou seja, a retenção, é o grande desafio de avaliação para os profissionais da comunicação.

Trabalho dos professores James Grunig e Linda Childers Hon, intitulado Guidelines for Measuring Relationships in Public Relations e publicado pela Comissão de Mensuração e Avaliação ${ }^{2}$ do Institute for Public Relations, estabelece critérios para mensuração do intangível.

No estudo, os autores apresentam seis elementos que compõem os relacionamentos: 1. o controle recíproco, 2. a confiança, 3. a satisfação, 4. o compromisso, 5. a troca de relacionamento e 6 . o relacionamento público. A partir deste conceito avaliam relacionamentos de longo prazo utilizando-se de metodologia quantitativa com a aplicação de um questionário de perguntas de concordância. Cria-se, a partir desta avaliação, uma pontuação para cada um dos seis elementos e, assim, é possível analisar a situação dos relacionamentos com cada um dos públicos estratégicos e compará-los entre si. Este é um dos modelos que tem sido aplicado na tentativa de tornar tangível a qualidade dos relacionamentos empresariais.

Paulo Nassar (2003, p. 45) afirma que o relacionamento está embasado na confiança e propõe uma pesquisa de natureza anárquica, para medir a confiança dos funcionários nas organizações. Sugere também que as pesquisas têm sido utilizadas para conhecer e controlar as pessoas das organizações. Seria a pesquisa uma ferramenta de gestão de controle de pessoas e não dos processos em si? O debate sobre as formas de medir e qual o âmbito dos resultados está longe de chegar ao fim.

\section{Auditoria de opinião: uma metodologia a se discutir}

Se auditoria de opinião pode ser considerada pesquisa é um assunto que ainda não foi devidamente esclarecido. Ao abordar o tema auditoria de opinião, Kunsch (2003, p. 306) cita autores e comenta a técnica de coleta de dados, que lança mão da entrevista em profundidade. Este recurso metodológico está no campo da pesquisa qualitati-

1 Fraser Likely é professor de MBA Executivo de Relações Públicas e Gestão da Comunicação na Universidade Royal Roads, Canadá, e especialista em métodos de mensuração de programas de Relações Públicas.

2 Esta Comissão, localizada no campus da Universidade da Flórida, reúne especialistas em mensuração e tem por objetivo disseminar as práticas de avaliação no âmbito da Comunicação Organizacional. Para maiores informações consultar: www.instituteforpr.com/measurement_commission.phtml 

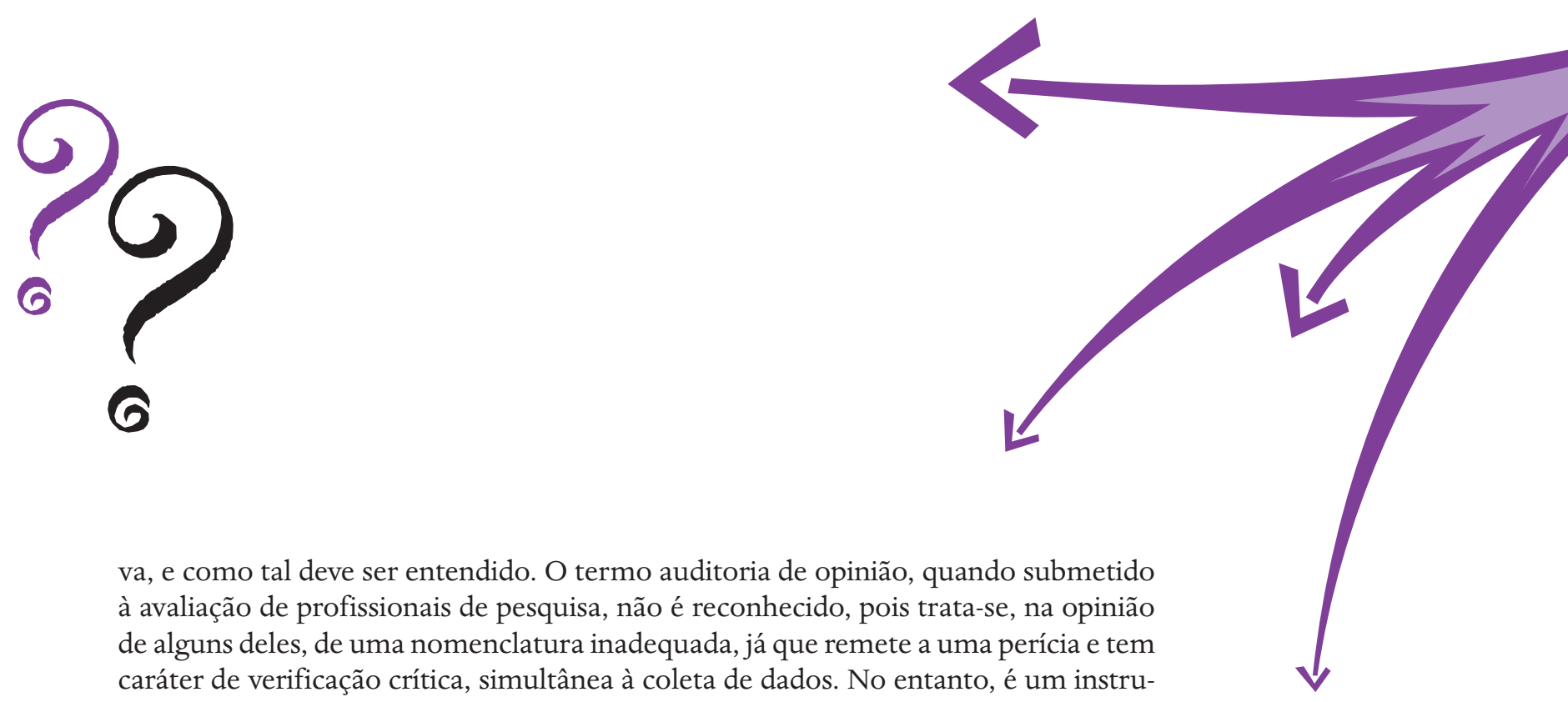

va, e como tal deve ser entendido. O termo auditoria de opinião, quando submetido à avaliação de profissionais de pesquisa, não é reconhecido, pois trata-se, na opinião de alguns deles, de uma nomenclatura inadequada, já que remete a uma perícia e tem caráter de verificação crítica, simultânea à coleta de dados. No entanto, é um instrumento para construção de diagnóstico que vem sendo utilizado por diversas assessorias de Relações Públicas e de Comunicação no Brasil.

A pesquisa qualitativa é uma metodologia com rigor técnico e que obedece a normas e a procedimentos que asseguram a veracidade dos resultados. O código de ética que rege os pesquisadores em todo o mundo, estabelecido pela European Society of Opinion and Marketing Research - Esomar, define questões comportamentais dos pesquisadores, além de uma experiência profunda na técnica.

Em seu livro Pesquisa de Marketing, os autores Aaker, Kumar e Day esclarecem que sentimentos, pensamentos, intenções só podem ser conhecidos com a utilização de pesquisa qualitativa. Por serem métodos menos estruturados, não devem ser substitutos dos estudos quantitativos, e sim serem utilizados como um prelúdio das informações.

Experiências junto a organizações no Brasil demonstram que nada substitui a credibilidade dos dados. Os gestores empresariais se comovem com gráficos e planilhas de resultados, mas duvidam da relevância de testemunhais e depoimentos. Para alinhar a comunicação aos seus BSC (Balanced Scorecards) e outros métodos de controle de resultados solicitam dados quantificáveis. Em muitos casos, a pesquisa quantitativa é inadequada ou até mesmo não recomendada e o trabalho de convencimento dos profissionais da comunicação torna-se um grande desafio.

Algumas exceções são feitas para o uso da pesquisa qualitativa como avaliação definitiva. Quando a população a ser pesquisada é pequena ou quando não é possível obter as informações desejadas por meio de um método quantitativo, utiliza-se como ferramenta única a pesquisa qualitativa. O modelo mais adequado recomendado por teóricos e pesquisadores de mercado é a utilização de metodologia mista, que contemple as vantagens das informações qualitativas com a segurança dos dados estatísticos da etapa quantitativa.

O mercado de comunicação no Brasil vive um momento de grande interesse pela mensuração e, particularmente, por indicadores de desempenho. O desenvolvimento de 
indicadores é um processo de levantamento de dados periódicos para estabelecer uma série histórica. Pressupõe ainda uma composição de informações, que, agregadas, demonstrem os caminhos a seguir.

Um modelo possível para a criação de um indicador de desempenho em comunicação interna seria composto de quatro fontes de informação: pesquisa de avaliação da comunicação, pesquisa de clima organizacional, taxa de turn over e desempenho financeiro da empresa. Para cada fonte de informação é atribuído um peso, que pode variar de empresa para empresa.

Tratando de um indicador de comunicação é recomendável um maior peso à pesquisa da área. No entanto, empresas que ainda não realizaram a etapa preliminar de coleta de dados desejam criar indicadores sem parâmetros básicos, numa construção inusitada que projeta o telhado sem fincar o alicerce.

\section{A pesquisa realizada pela Aberje}

A Associação Brasileira de Comunicação Empresarial - Aberje é uma entidade cuja visão é ser um centro de excelência na produção de conhecimento e práticas de gestão estratégica em Comunicação Organizacional. Uma das atividades da Aberje é a produção de estudos sobre temas de interesse dos profissionais e, neste ambiente, nasceu a idéia de mapear a realidade com o estudo Uso da Pesquisa na Comunicação Corporativa.

A primeira questão que se colocou foi sobre o escopo do projeto. Quem seriam os informantes? O estudo começou a se desenhar, em meados de 2003, nas discussões internas no Instituto Aberje de Pesquisa, cuja entidade que o abriga reúne, entre seus associados, parcela significativa de empresas de grande porte no país, todas elas com equipes estruturadas de comunicação empresarial. Em tese, deveriam ser grandes usuárias da pesquisa.

\section{A metodologia}

As soluções para a formatação do estudo foram se apresentando conforme as discussões tomavam corpo. O projeto original, com metodologia quantitativa, previa cem entrevistas com empresas selecionadas do cadastro das 500 Maiores e Melhores da revista $E_{x a m e}$. O resultado com uma centena de empresas representativas certamente se-

3 A publicação 500 Maiores e Melhores Empresas, organizada pela Editora Abril, é editada nos moldes da revista norte-americana Fortune, com dados fornecidos pelas empresas. Foi utilizada a base de dados de 2003. 
ria um excelente sinalizador do uso da pesquisa como instrumento de mensuração das atividades da comunicação corporativa no país.

A técnica de coleta de dados escolhida foi um questionário estruturado, com questões fechadas, encaminhado via e-mail ao responsável pela comunicação corporativa da empresa respondente, seguido de contato telefônico.

Logo no início do levantamento das informações identificou-se a necessidade de ouvir também as assessorias de comunicação, que muitas vezes recomendam e, em alguns casos, realizam processos de avaliação. Decidiu-se, então, incluir cerca de quarenta assessorias selecionadas entre associados da Aberje, de diferentes regiões do país. Foram conduzidas entrevistas pessoais em profundidade e algumas em semiprofundidade por telefone, que contribuíram com cases e informações sobre processos de investigação. Pela representatividade das assessorias consultadas, a equipe do Instituto Aberje de Pesquisa considera que os resultados são o retrato fiel do que se pratica em termos das técnicas de avaliação de comunicação no país.

Conforme o estudo caminhava, novas questões se apresentaram e optou-se por ouvir também os institutos de pesquisa. Contribuíram com suas informações vinte institutos nacionais e internacionais representativos. Profissionais de reconhecida competência e conhecimento técnico foram ouvidos e transmitiram informações valiosas, apresentaram metodologias e se mostraram muito interessados no segmento da comunicação corporativa. Parte dos resultados da pesquisa já começava ali. Descobriuse que os institutos sabem pouco sobre comunicação corporativa, e constatou-se a suspeita de que, na comunicação corporativa, sabe-se menos ainda sobre os institutos de pesquisa.

A cada entrevista uma nova referência, um nome, um profissional a mais para ouvir. Chegou-se assim ao conceito de metapesquisa, que é um estudo incomum no qual a pesquisa é o sujeito, o verbo e o objeto em si mesma.

\section{Planejar e avaliar: dois objetivos da pesquisa}

A etapa quantitativa do estudo Uso da Pesquisa na Comunicação Corporativa é um retrato de cem empresas, cuja base das 500 Melhores e Maiores de Exame recortou as empresas de grande porte. A amostra contou com 9,8\% de empresas com até quinhentos funcionários, $35 \%$ entre mil e cinco mil funcionários e $47 \%$ acima de cinco mil funcionários.

As empresas ouvidas contemplaram os ramos da indústria, do comércio e da prestação de serviços. Quando consultadas sobre a freqüência de uso da pesquisa no planejamento, 31,3\% das empresas afirmaram que raramente ou nunca a utilizam, como se vê no Gráfico 1. Muito embora a maioria das empresas afirme utilizar a pesquisa, 
é importante registrar que aproximadamente um terço das empresas planeja ações de comunicação sem pesquisar.

\section{Gráfico 1 - Freqüencia de pesquisa no planejamento}

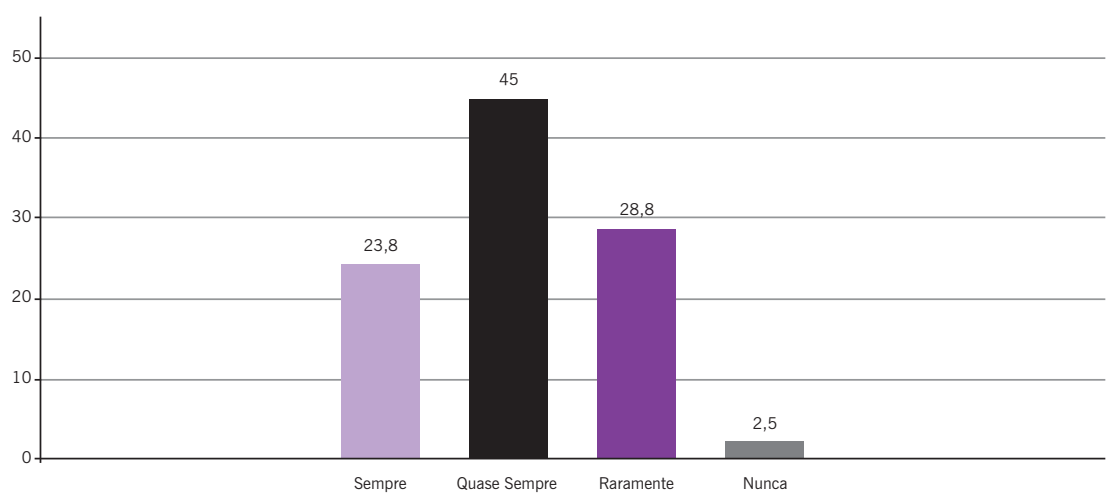

Fonte: Instituto Aberje de Pesquisa

Quando a questão refere-se à utilização de pesquisa para avaliação de programas e ações de comunicação, a situação se repete, como demonstrado no Gráfico 2. Uma das publicações de referência ${ }^{4}$ sobre pesquisa em Relações Públicas, editada pelo Institute for Public Relations da Universidade da Flórida, registra como primeira regra de mensuração o estabelecimento, antes de começar, das metas definidas para os programas e atividades, de modo a poder fixar os resultados desejados.

Este é o pressuposto do planejamento da pesquisa de avaliação. Para que se possa identificar se um programa de comunicação corporativa foi bem ou mal-sucedido é necessário que se tenha estabelecido, antecipadamente, as metas que se desejava atingir.

A gama diversificada de públicos que se relacionam com uma empresa sugere que o profissional da comunicação detenha conhecimento das necessidades específicas de cada um desses stakeholders. Quando os entrevistados foram questionados sobre as maiores demandas de pesquisa na empresa, o público interno foi o primeiro colocado, com $29,4 \%$ das citações, seguido dos clientes, com 25\% (Gráfico 3).

4 Guidelines for Measuring the Efectiveness of PR Programs and Activities, publicado pelo Insittute for Public Relations 
As assessorias de comunicação também afirmaram que o público interno tem sido o alvo principal para a pesquisa, seja para avaliar campanhas internas, seja para mensurar os meios de comunicação interna.

Os colaboradores, ou capital humano como preferem os economistas, são foco de várias pesquisas. Uma das interpretações possíveis é a facilidade de execução, e outra é

\section{Gráfico 2 - Freqüência de pesquisa na avaliação}

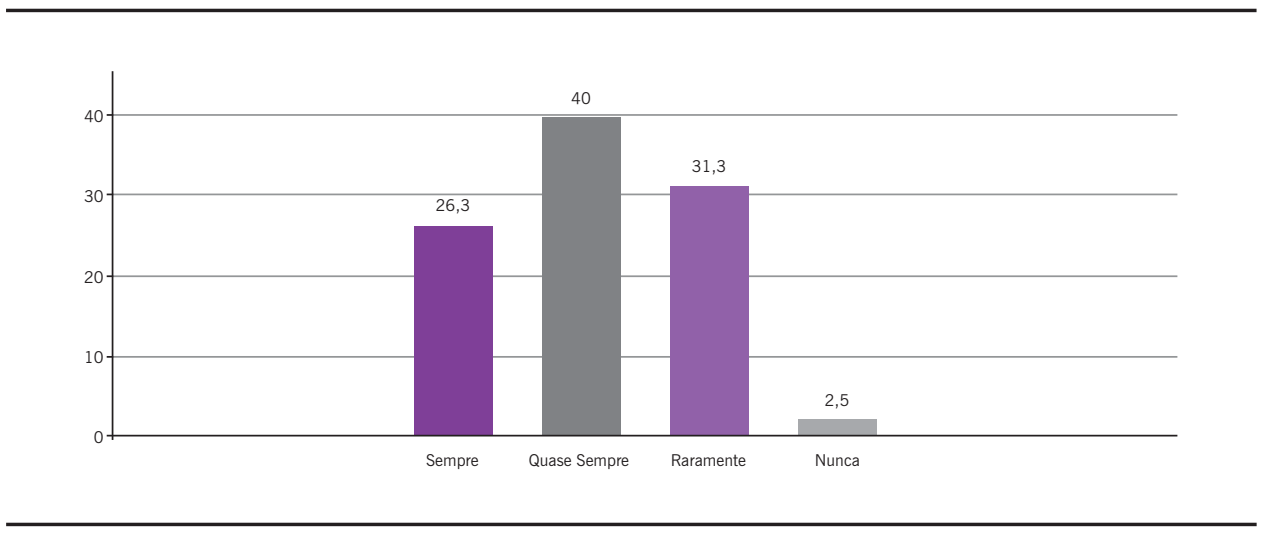

Fonte: Instituto Aberje de Pesquisa

\section{Gráfico 3 - Área que usa mais pesquisa}

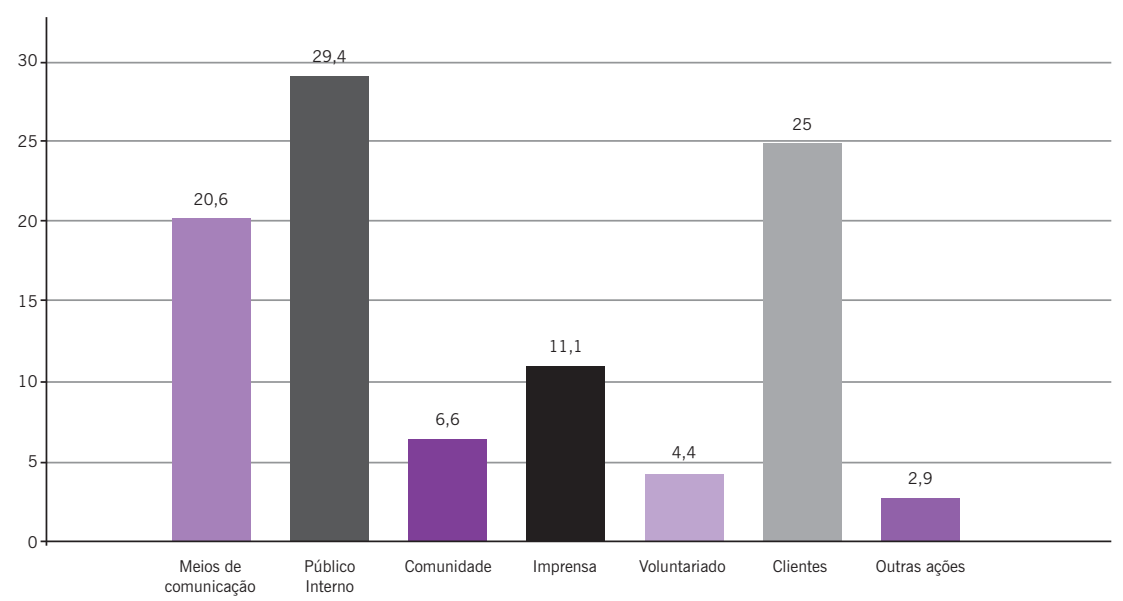

Fonte: Instituto Aberje de Pesquisa 
a necessidade de identificar o estado de ânimo dos funcionários. As pesquisas de clima organizacional, realizadas por quase todas as empresas de grande porte, já estão decididamente incorporadas ao cotidiano das organizações. Um dos quesitos avaliados nessas pesquisas de clima é a comunicação. Portanto, pesquisar temas ligados à comunicação não é novidade nessas empresas.

Os entrevistados foram questionados sobre a freqüência da pesquisa de clima nas organizações onde trabalham, prática adotada por muitas empresas como ferramenta de gestão dos recursos humanos. Em 41,3\% delas a pesquisa de clima é realizada anualmente, a cada dois anos em $31,3 \%$, em $3,8 \%$ dos casos a cada três anos e $15 \%$ afirmaram que a pesquisa não tem periodicidade definida. Apenas $6,3 \%$ das empresas nunca realizaram pesquisa de clima organizacional. Nota-se que a pesquisa de recursos humanos é mais disseminada que a pesquisa de comunicação.

As chamadas auditorias de opinião, muito citadas pelos profissionais das assessorias de comunicação e criticadas pelos entrevistados dos institutos, foram mencionadas por $17,9 \%$ dos profissionais consultados como a metodologia de pesquisa que adotam para diagnóstico e avaliação, tal como se observa no Gráfico 4.

O perfil dos profissionais que responderam à pesquisa foi principalmente de gestores da comunicação, sendo $15 \%$ de diretores, $48,8 \%$ de gerentes e $36,6 \%$ de coordenadores, analistas ou supervisores. Quando questionados sobre qual era a maior dificuldade na realização de pesquisas, quase todos indicam alguma dificuldade. No Gráfico 5 , nota-se que as dificuldades permeiam todo o processo de pesquisa, com maior ou menor intensidade, começando no planejamento e escolha da metodologia até chegar à análise dos resultados.

\section{Gráfico 4 - Metodologia mais utilizada}

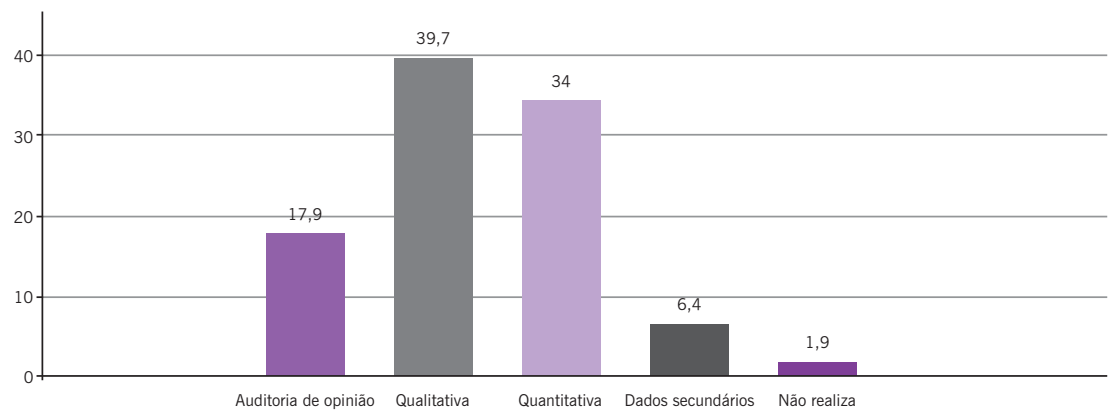

Fonte: Instituto Aberje de Pesquisa 
A metodologia, apontada por $17,6 \%$ dos profissionais como principal dificuldade, é a base da pesquisa (Gráfico 5). A escolha equivocada do método pode distorcê-lo e, assim, invalidar todos os resultados dele originados.

Um quarto dos entrevistados afirmou que não tem dificuldade para realizar pesquisas.

\section{Gráfico 5 - Maior dificuldade}

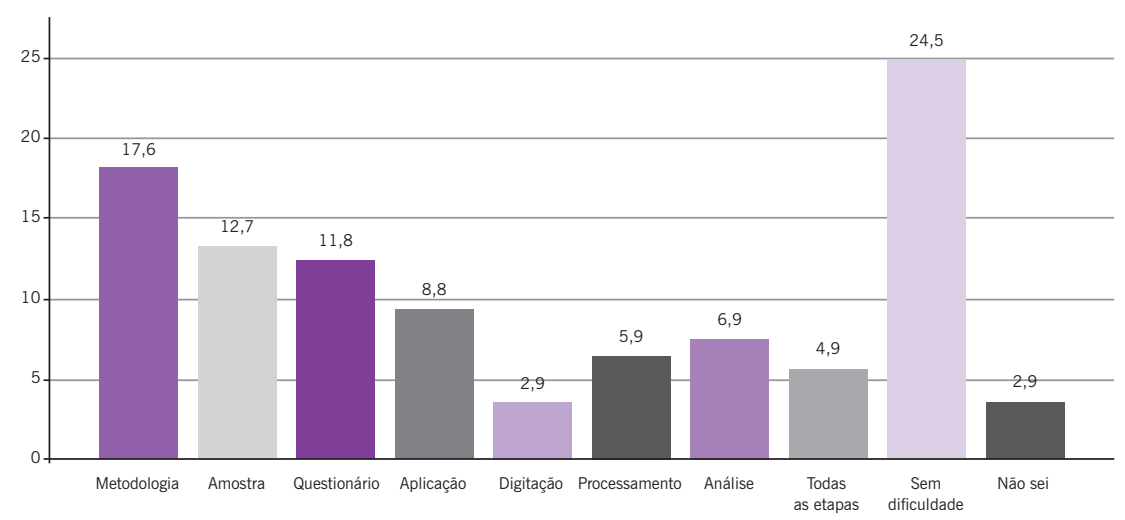

Fonte: Instituto Aberje de Pesquisa

\section{Gráfico 6 - Quem faz a pesquisa}

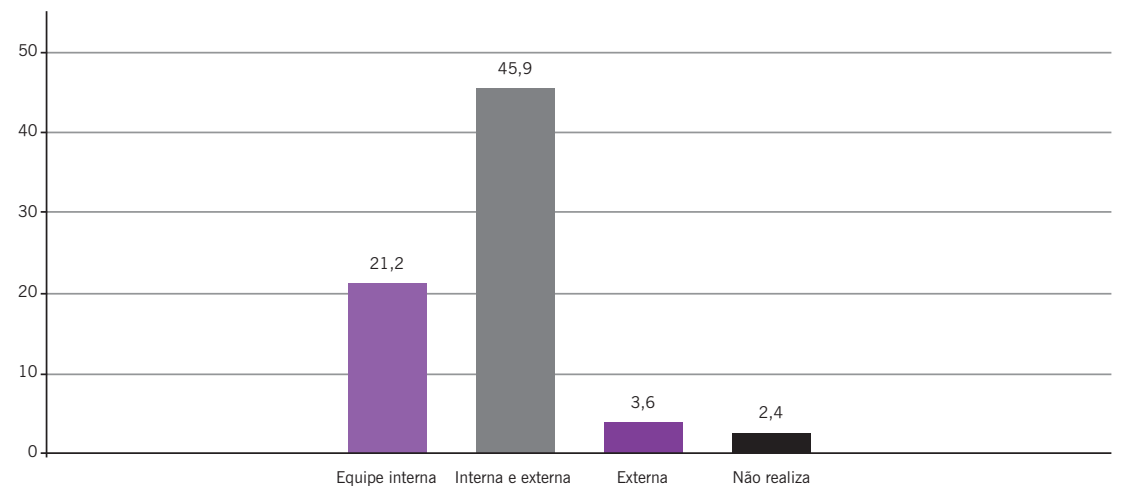

Fonte: Instituto Aberje de Pesquisa 
Cerca de metade das empresas (45,9\%) trabalham com equipes mistas - internas e externas - para a realização de pesquisas, e $21,2 \%$ afirmaram que atuam com equipes internas, como ilustrado no Gráfico 6.

Quando consultados sobre o grau de informação que as equipes internas têm sobre pesquisa, apenas $13,7 \%$ afirmaram que a equipe está preparada para conduzir as pesquisas, enquanto $37,4 \%$ mencionaram que a equipe tem conhecimentos básicos do assunto (Gráfico 7).

Os entrevistados também foram questionados sobre os métodos utilizados para coleta de dados. Os resultados demonstrados no Gráfico 8 sugerem que as etapas metodológicas não foram rigorosamente observadas. Ora, se 57,6\% das empresas usam pesquisas qualitativas/ auditoria de opinião, como explicar métodos de coleta essencialmente quantitativos? Do ponto de vista metodológico não é possível fazer pesquisas qualitativas com auto preenchimento, pela Internet ou pelo telefone. Trata-se de um viés de informações com impacto muito grande nos resultados.

A pesquisa qualitativa é realizada com técnicas de coleta de dados distintas: as entrevistas em profundidade e os grupos de discussão. Os grupos de discussão, muito utilizados em pesquisas de Marketing e de opinião pública, foram citados poucas vezes tanto pelas empresas quanto pelas assessorias de comunicação.

Um dos aspectos que chama a atenção neste estudo é a relação entre o uso da pesquisa como ferramenta e a estrutura de comunicação das empresas. O estudo contem-

\section{Gráfico 7 - Perfil da equipe de pesquisa}

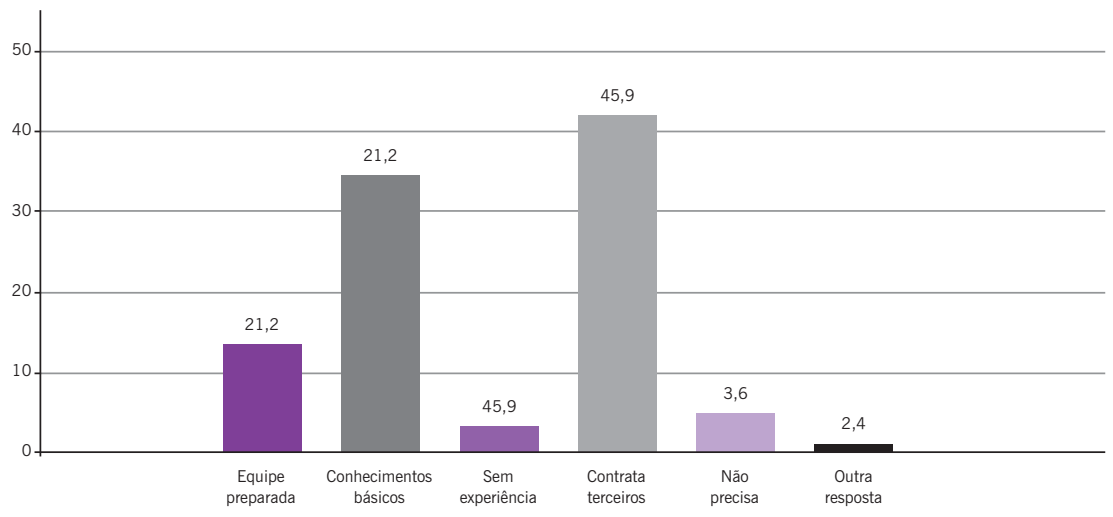

Fonte: Instituto Aberje de Pesquisa 
plou grandes organizações, nas quais a comunicação já tem espaço definido e ocupa posição de destaque. Em um terço delas trata-se de uma diretoria e em $43,8 \%$ dos casos é uma gerência, como se verifica no Gráfico 9.

\section{Gráfico 8 - Método de coleta}

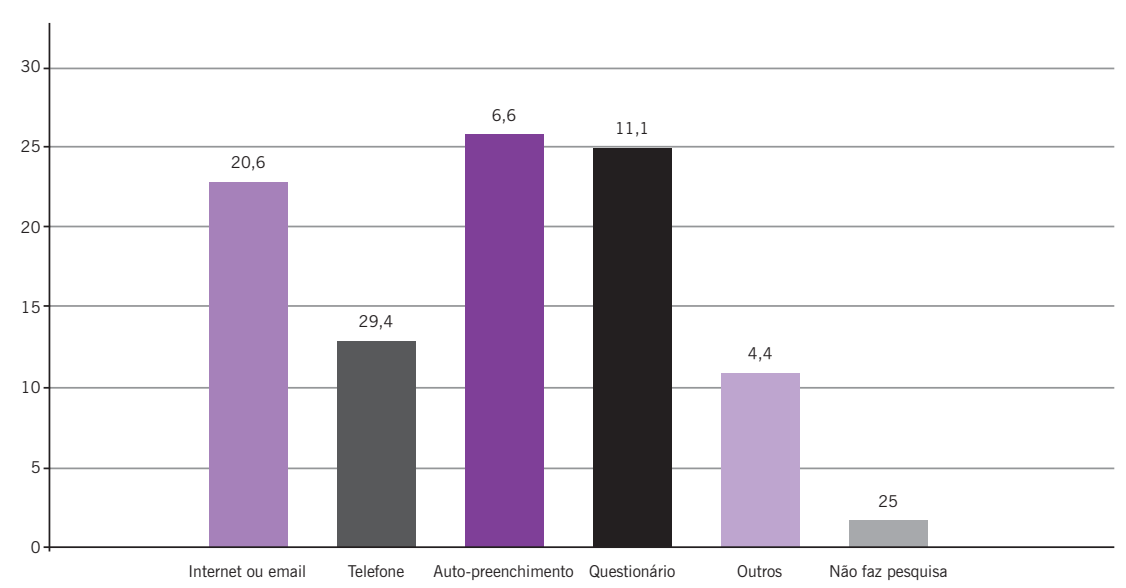

Fonte: Instituto Aberje de Pesquisa

\section{Gráfico 9 - Comunicação corporativa}

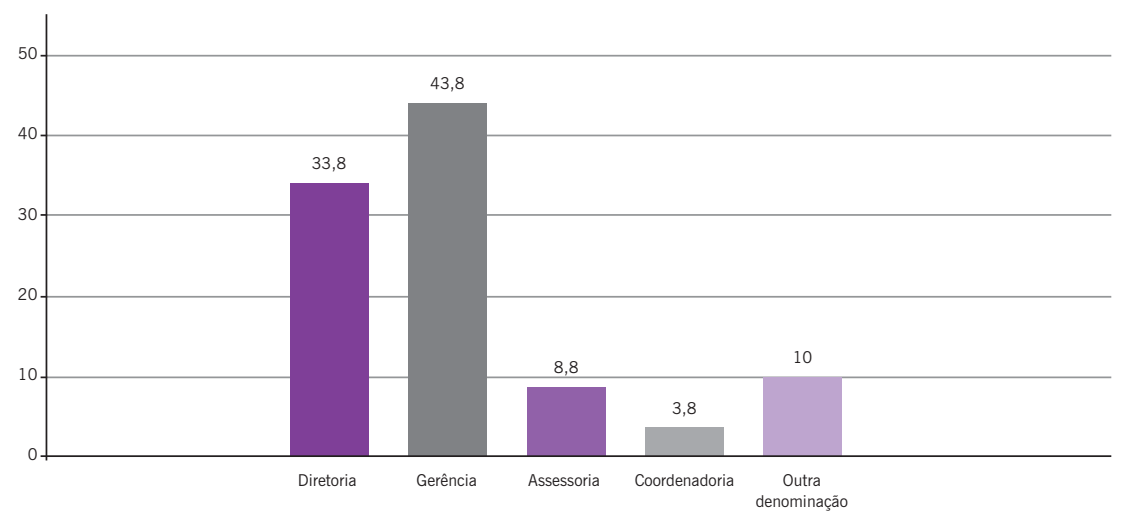

Fonte: Instituto Aberje de Pesquisa 
As tendências de gestão são disseminadas pelas grandes empresas, que saem na frente e depois se tornam benchmarking para as outras empresas do mercado. Nessa questão do uso da pesquisa, os modelos ainda estão se delineando. Se, por um lado, persiste a sensação de que a área de Relações Públicas no Brasil está em descompasso com as tendências internacionais, por outro existem sinais claros de que as empresas estão no rumo certo. O momento parece ser de aprendizado, já que não é possível desenvolver uma competência evitando o processo doloroso da tentativa e erro.

\section{Caminhos que levam a qualquer lugar}

A pesquisa é uma atividade que requer conhecimentos específicos, pressupõe o domínio das metodologias, noções de estatística, experiência de campo, dentre outras competências. No entanto, na área de comunicação não é percebida em toda sua complexidade. Prova disto, além da informação de que $34,7 \%$ das equipes nas empresas têm conhecimentos básicos e ainda assim realizam pesquisas, é que também as assessorias de comunicação trabalham com equipes próprias.

O grande equívoco do cliente e da agência quando decidem pela pesquisa caseira é a sensação de despesa que causa a contratação de um instituto de pesquisa ou consultor. Pesquisas realizadas sem metodologia ou com amostras mal desenhadas podem levar a tamanho grau de distorção que acabam por inviabilizar a utilização dos dados obtidos. Os resultados são permeados de credibilidade, mais ainda quando se utiliza o método quantitativo. Afinal, os dados têm um poder muito grande na formação da opinião das pessoas. O grande risco é de o profissional de comunicação tomar uma decisão baseada em dados errados, acreditando na veracidade das informações.

Planejar sem dados de pesquisa é como tomar qualquer estrada nos caminhos de Alice. Afinal qualquer caminho serve, se o profissional de comunicação não sabe para onde ir. A analogia com o texto de Lewis Caroll no início deste artigo não foi exatamente um recurso de linguagem com o intuito de chamar a atenção do leitor. Charles Lutwidge Dodgson, nome verdadeiro de Lewis Caroll, era matemático, professor em Oxford e fascinado por lógica.

Um dos traços característicos da lógica de Charles Dodgson era o seu interesse pelos jogos capazes de testar a razão. Explorando os limites da linguagem simbólica, ele revelou o nonsense e a lógica matemática.

O simbolismo de Alice no País das Maravilhas veste bem o figurino do profissional de comunicação. Através dos espelhos não se vê a realidade, apenas o reflexo dela. Na comunicação corporativa, o profissional percorre o campo de relacionamentos abstratos e trabalha com a questão da imagem, de dificil mensuração. Lewis Carroll ou Charles 
Dodgson nos ensina que a lógica matemática e o mundo simbólico se encontram para explicar os fenômenos que afetam o ser humano.

Mais pragmático que Lewis Carroll, Peter Drucker afirma que a lógica, por si só, é essencialmente estúpida, mas lembra que, se um profissional não pode medir um processo, também não pode gerenciá-lo. Peter Drucker e Alice, no entanto, têm uma coisa em comum: quando tiver que tomar uma decisão sobre para onde ir, pergunte, pesquise. A menos que não faça diferença qual o caminho a seguir.

\section{Bibliografia}

AAKER, D. A.; KUMAR, V. e DAY, G. S. Pesquisa de Marketing. São Paulo: Atlas, 2001.

BERGER, A. A. Media and Communication Research Methods: An Introduction to Qualitative and Quantitative Approaches. Thousand Oaks, CA: Sage Publications, 2000.

CLANLAT, J.-F. Ciências Sociais e Management. São Paulo: Atlas, 1999

FREY, L.; BOTAN, C. e KREPS, G. Investigating Communication: An Introduction to Research Methods. Englewood Cliffs, NJ: Prentice Hall, 1991.

GRUNIG, J. E. e HON, L. C. Guidelines for Measuring Relationships in Public Relations. Florida: Institute for Public Relations, 1999.

KUNSCH, M. M. K. Planejamento de Relações Públicas na Comunicação Integrada. Ed. ver., ampl. e atual. São Paulo: Summus, 2003.

LIKELY, F. Communications and PR: Made to Measure. Disponível na Internet www.instituteforpr.com/measurement_and_evaluation, 2002

LINDERMANN, W. K. Let's Put Meaning into Public Relations Research (Online) Disponível na Internet www.instituteforpr.com/research_methods, 2002.

Public Relations Research for Planning and Evaluation (online) Disponível na Internet www.institute-

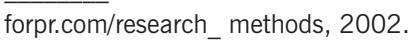

NASSAR, P. Tudo é comunicação. São Paulo: Lazuli, 2003. 